\title{
Plane strain compression behaviour and localization of deformation of $\mathrm{MH}$-bearing sand
}

\author{
A. Kato ${ }^{\text {i) }}$ and Y. Nakata ${ }^{\text {ii) }}$ \\ i) Ph.D Student, Department of Civil Engineering, Yamaguchi University, Tokiwadai 2-16-1, Ube, 755-8611, Japan. \\ ii) Professor, Department of Civil Engineering, Yamaguchi University, Tokiwadai 2-16-1, Ube, 755-8611, Japan.
}

\begin{abstract}
As a result of recent investigations, carried out mainly by the $\mathrm{MH} 21$ research consortium of Japan, methane hydrate, referred to hereafter as "MH", is expected to become a possible future energy resource. In order to evaluate the stability of the seabed during MH production, previous research on the mechanical properties of MH-bearing sand have been conducted under triaxial stress conditions. However, these were very specific conditions whereas several stress conditions are assumed to exist in the Nankai Trough where $\mathrm{MH}$ production is carried out. Therefore it is essential to consider these stress conditions in order to understand the changes in stress and deformation behavior of the seabed. In this study, we describe the effects on MH-bearing sand under plane strain conditions with changing confining pressure. The apparatus used for plane strain tests has both a confining plate and an observation window. Local deformation of MH-bearing sand is shown using photographs of specimens taken during shear tests.

A marked increase in the stress ratio of the host sand (Toyoura sand) and MH-bearing sand was more apparent in the plane strain tests than in the triaxial tests. The stress ratio decreased dramatically after the appearance of the peak stress ratio. Moreover, the peak stress ratio of MH-bearing sand was higher than that of the host sand as shown in previous research. After shear, in the case of the host sand, particle crushing increased as the effective confining pressure increased. Additionally, more particle crushing occurred inside the shear band than outside. In the case of the host sand, the failure strength for plane strain tests shifted from the SMP criterion to the Mohr-Coulomb criterion as the effective confining pressure increased, due to particle crushing. In the case of MH-bearing sand, the failure strength for every effective confining pressure lay between the SMP criterion and Mohr-Coulomb criterion. Expansive volumetric dilation increased within the shear band as the axial strain increased for each case, with more dilation occurring for MH-bearing sand compared with host sand.
\end{abstract}

Keywords: plane strain, localization, high pressure, particle crushing

\section{INTRODUCTION}

Methane hydrate, referred to hereafter as "MH", is a metastable solid material that consists of methane gas $\left(\mathrm{CH}_{4}\right)$ and water molecules. It is known to exist in a stable condition under certain temperature and pressure conditions. Its existence has been confirmed in permafrost layers and in deep ocean floors which satisfy the stable conditions of MH [Kvenvolden, 1993].

MH which exists in pore spaces can be largely grouped into three types: pore filling, load bearing and cementing [Waite, 2009]. Though it is not clear how MH exists in the sediments, it has been found that high $\mathrm{MH}$ saturation leads to increased strength in the sediments [e.g. Masui et al., 2008]. Yun et al., [2009] has described the mechanical properties of gas hydrate-bearing sand, silt and mud, using tetrahydrofuran (THF) instead of methane. These results indicated that the increase in shear strength was small for THF-hydrate saturation ratios less than $40 \%$, but a marked increase in shear strength was observed when the saturation ratios exceeded 40\%. Likewise, [Miyazaki et al., 2007] has demonstrated that MH-bearing sand has a loading rate dependency, performing consolidated drained compression tests at various strain rates. Furthermore, it has become apparent that an increase in $\mathrm{MH}$ in specimens of Toyoura sand leads to an increase in strength [Miyazaki et al., 2010, 2011]. Therefore, it is commonly believed that $\mathrm{MH}$ has cement-like properties.

The experiments in the above papers have been conducted under triaxial stress conditions. However, these were specific conditions which are different from in-situ conditions. It is essential to consider the in - situ stress conditions in order to understand the changes in actual stresses and deformation behaviour. In this study, we describe the effects on MH-bearing sand under plane strain conditions with various confining pressures.

Moreover, in previous research the deformation of specimens during tests could not be observed due to the test apparatus being made of thick stainless steel in order to tolerate high pressure. Consequently, the deformation of specimens was represented as a total average volume change. In the past, experimental studies have focused on strain localization in various tests [e.g. Roscoe 1970, 
Arthur et al., 1977, Desrues et al., 1985, Tatsuoka et al., 1990] in order to investigate the local deformation of a soil mass or sand specimen. From the results, it appeared that volumetric expansion occurred inside the shear band while other areas showed almost no volume change. In addition, the experiments in the above papers were performed under low confining pressure and pore pressure, not under high pressure conditions. The apparatus we used for the plane strain tests has both a confining plate and an observation window. Also, this apparatus can reproduce deep seabed pressures and temperatures. Local deformation of $\mathrm{MH}$-bearing sand is shown using photographs of specimens taken during shear tests. Image analysis was performed on these pictures in order to obtain quantitative data of local strain.

\section{METHOD}

Toyoura sand was chosen as the host sand and the water content was calculated based on the desired density and level of $\mathrm{MH}$ saturation. Moist soil was arranged in 12 layers in a silicon membrane and mold, with each layer compacted by a tamper. After forming the specimen, a confining pressure of $0.2 \mathrm{MPa}$ was

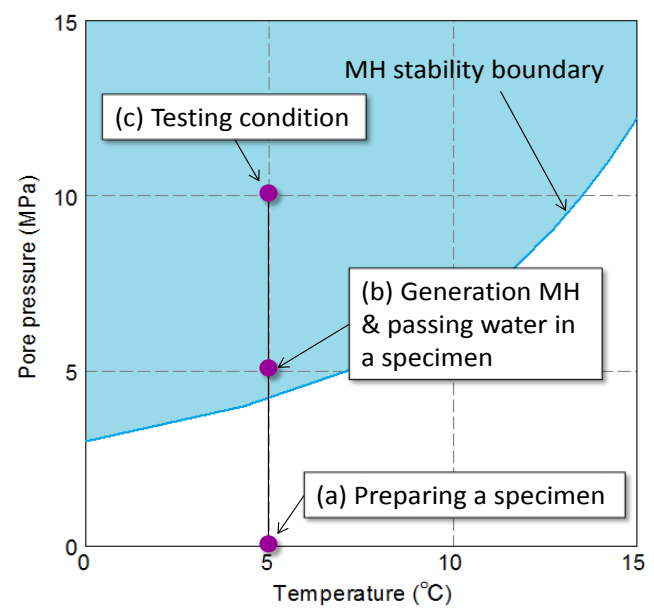

Fig. 1. State paths for pressure and temperature to prepare test conditions.

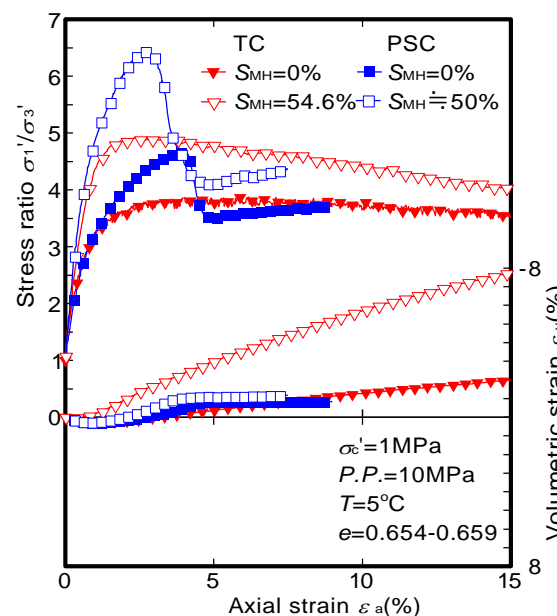

(a) $\sigma_{3}^{\prime}=1 \mathrm{MPa}$

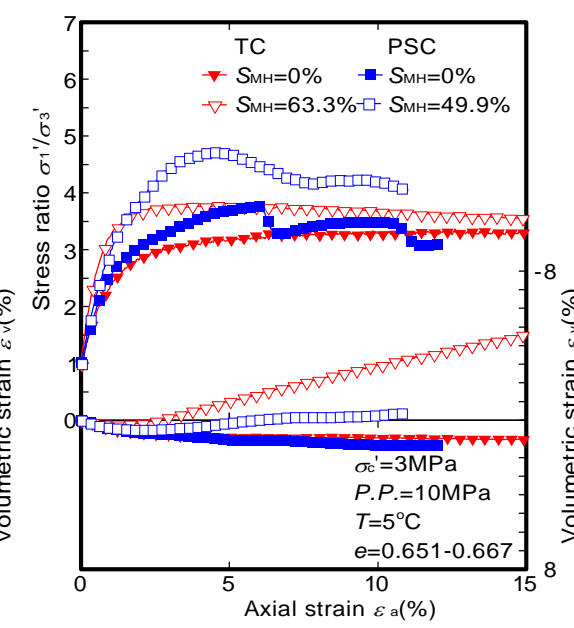

(b) $\sigma_{3}^{\prime}=3 \mathrm{MPa}$ applied to the specimen in order to keep it self-standing (Fig. 1a). Next, methane gas was injected into the specimen in order to generate $\mathrm{MH}$ in the $\mathrm{MH}$ stability zone, which was at a set temperature of $5^{\circ} \mathrm{C}$. A differential pressure of cell pressure minus pore pressure was kept at $0.2 \mathrm{MPa}$ while these pressures were increased. After generating $\mathrm{MH}$, methane gas remaining in pore spaces was replaced with water to give water saturated condition. During generating of $\mathrm{MH}$ and passing of water through the specimen, pore pressure and cell pressure were kept at $5 \mathrm{MPa}$ and $5.2 \mathrm{MPa}$, respectively (Fig. 1b). Then, the pore pressure was increased to $10 \mathrm{MPa}$ with the effective confining pressure kept at $0.2 \mathrm{MPa}$. After that, the specimen was consolidated to the prescribed stress conditions, and then shear testing was performed at constant temperature and confining pressure (Fig. 1c).

\section{COMPRESSION TEST RESULTS}

\subsection{Compression behavior of MH-bearing sand}

Figure $2 \mathrm{a}$ shows the stress ratio $\left(\sigma_{1}{ }^{\prime} / \sigma_{3}{ }^{\prime}\right)$, axial strain and volumetric strain relationships at an effective confining pressure $\sigma_{3}^{\prime}$ of $1 \mathrm{MPa}$. The triaxial compression test (TC) results are from Hyodo et al. [2013], who carried out the tests using a triaxial testing apparatus which could control temperature and pressure. "PSC" will be used hereafter to refer to plane strain compression tests. Both TC and PSC were carried out in conditions under which the saturation of methane hydrate $\left(\mathrm{S}_{\mathrm{MH}}\right)$ was equal to $0 \%$ or around $50 \%$. The reason for generating $S_{\mathrm{MH}}$ to around $50 \%$ was in order to clarify the differences in behavior between host sand and MH-bearing sand. In Fig. 2a, the strength increases with increasing $\mathrm{S}_{\mathrm{MH}}$. The peak stress ratios are not clear in the TC results, thus the peak stress ratios are taken to be almost the same as the residual stress ratios. For PSC results, however, there is a marked increase in the peak stress ratios of host sand and $\mathrm{MH}$-bearing sand. The stress ratio decreases dramatically after the appearance

Fig. 2 Stress ratio-strain curve comparing triaxial compression tests and plane strain compression tests. 


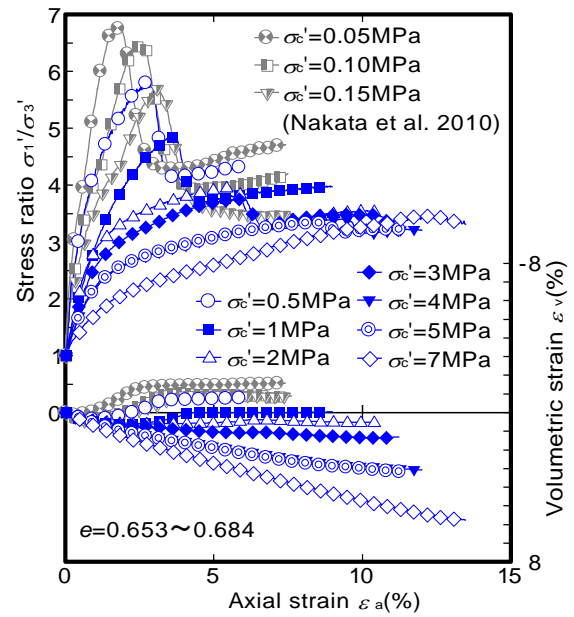

Fig. 3 Stress ratio-strain curve for host sand in plane strain compression tests.

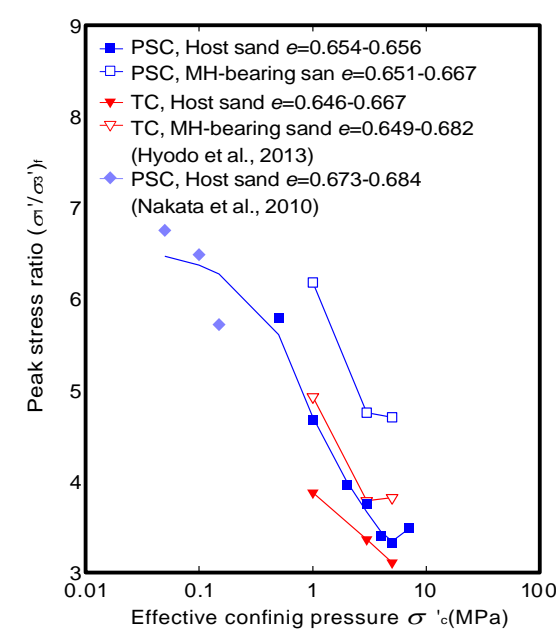

(a)

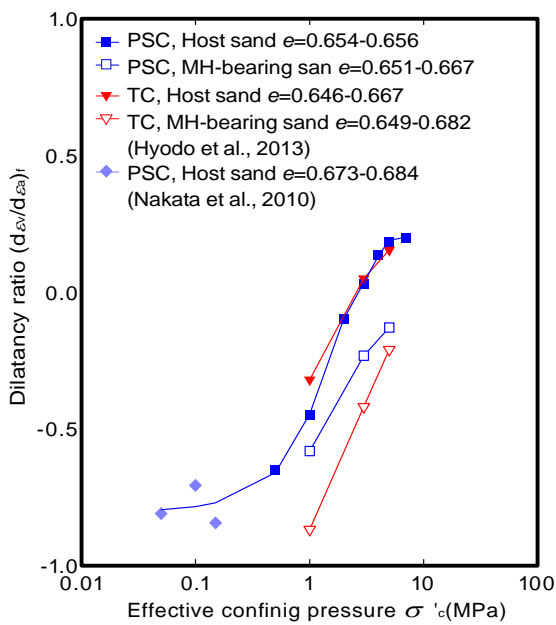

(b)

Fig. 4 Effects of confining pressure on peak stress ratio and dilatancy ratio.

of the peak stress ratio. Considering the volumetric strain for TC, the dilative behavior of MH-bearing sand occurs more markedly than that of host sand. From the PSC results, the volumetric strain of MH-bearing sand is only slightly higher than that of pure sand, even though $\mathrm{MH}$ was included in the specimen. Additionally, the volumetric strain becomes steady after nearing the residual stress ratio. Figure $2 \mathrm{~b}$ and Fig. $2 \mathrm{c}$ show the stress ratio $\left(\sigma_{1}{ }^{\prime} / \sigma_{3}{ }^{\prime}\right)$, axial strain and volumetric strain relationships when the effective confining pressure $\sigma_{3}{ }^{\prime}$

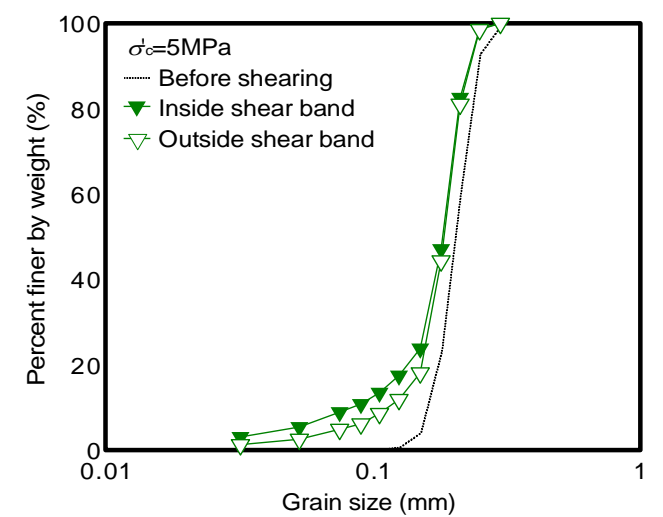

Fig. 5 Distribution curve before and after shearing..

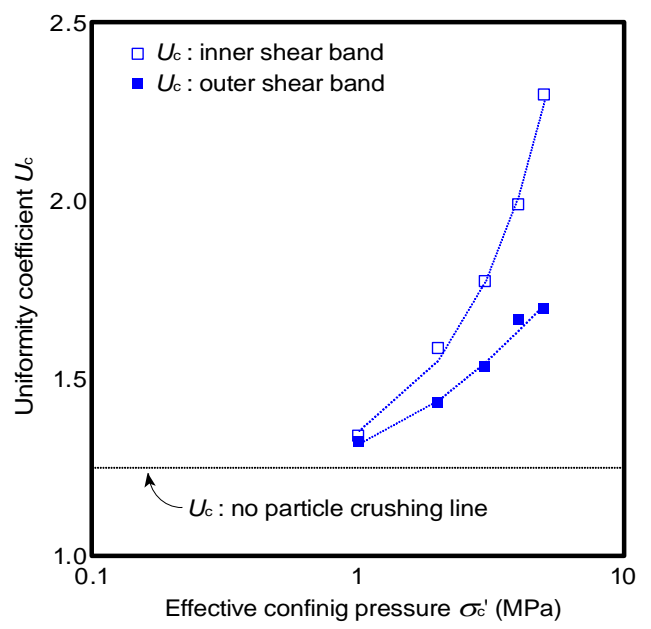

Fig. 6 Effect of confining pressure on particle crushing. is at $3 \mathrm{MPa}$ and $5 \mathrm{MPa}$, respectively. As mentioned above, the stress ratio and dilative behavior increase is due to MH cementation. It should be emphasized that the peak stress ratio decreases and the axial strain at the point of the peak stress ratio increases with increasing confining pressure. An increase in confining pressure also leads to the peak stress ratio becoming gradually closer to the residual stress ratio in the case of host sand in PSC. In addition to this, the compressive behavior during PSC is almost the same as that during TC for the host sand. In the same way as the host sand, the axial strain at the point of the peak stress ratio for MH-bearing sand also increases with increasing confining pressure, however the results for the volumetric strain are not almost equal for TC and PSC tests on MH-bearing sands as they were with host sand.

Figure 3 shows the stress ratio $\left(\sigma_{1}{ }^{\prime} / \sigma_{3}{ }^{\prime}\right)$, axial strain and volumetric strain relationships for the host sand at every confining pressure. Plane strain test results performed by Nakata et al. [2010] at low confining pressure are also shown in this figure. From Fig. 3, it is clear that the peak stress ratio decreases and the volumetric strain gradually translates from dilative behavior to compressive behavior as confining pressure increases. Furthermore, it should be noted that the volumetric strain indicates compressive behavior during shearing between $\sigma_{3}{ }^{\prime}=3 \mathrm{MPa}-7 \mathrm{MPa}$, even though a peak stress appears. Figure $4 \mathrm{a}$ shows the relationship between effective confining pressure and peak stress ratios from the results in Fig. 2 and Fig. 3. As mentioned above, the peak stress ratio decreases as confining pressure increases. In the case of the host sand, similar results were gained from the PSC and TC tests. The results show a similar tendency at the same void ratio for both PSC and TC, and as such it is possible that the results of PSC can be represented by shifting TC results upwards. Figure $4 \mathrm{~b}$ shows the relationship between effective confining pressure and dilatancy ratio at peak stress. From the figure, it can be seen that host sand follows a similar trend in both PSC and TC. The dilatancy ratio of 


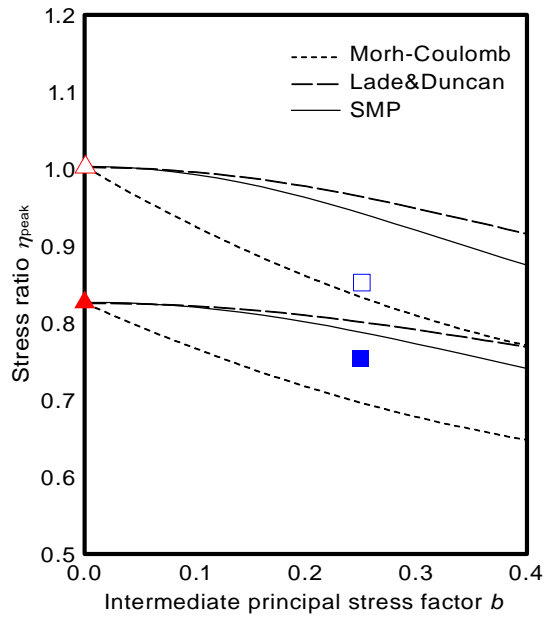

(a) $\sigma_{3}^{\prime}=1 \mathrm{MPa}$

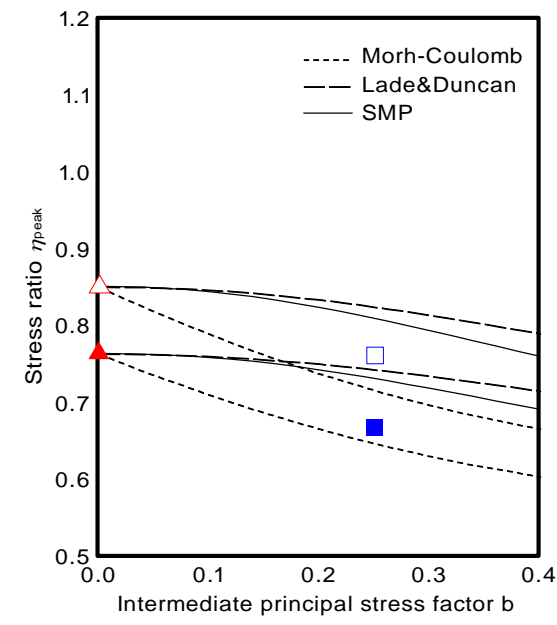

(b) $\sigma_{3}^{\prime}=3 \mathrm{MPa}$

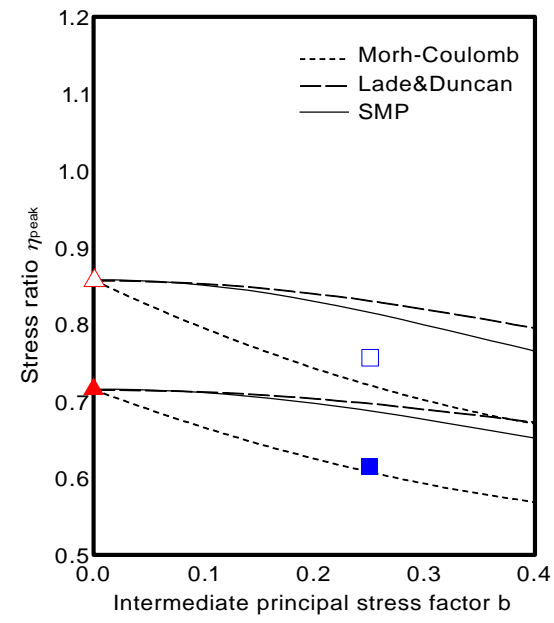

(c) $\sigma_{3}^{\prime}=5 \mathrm{MPa}$

Fig. 7 Stress ratio-strain curve compared with triaxial compression tests and plane strain compression tests.

MH-bearing sand in PSC and TC is lower than that of the host sand.

After shearing, the amount of particle crushing due to shearing was investigated. For this, the area inside the shear band was extracted separately from the rest of the sample. Figure 5 shows the grain size distribution before and after shear at $\sigma_{3}{ }^{\prime}=5 \mathrm{MPa}$. From the figure, it can be seen that more particle crushing occurred within the shear band than the area outside. Figure 6 shows the relationship between effective confining pressure and the uniformity coefficient. The uniformity coefficient $U_{c}$ is calculated separately for the inside and outside of the shear band after shearing. From Fig. 6 it can be seen that $U_{\mathrm{c}}$ as well as the difference in $U_{\mathrm{c}}$ inside and outside of the shear band increases as confining pressure increases.

\subsection{Application for the failure criterion}

The peak stress ratio $\eta_{\text {peak }}$ for plane strain compression tests can be predicted by applying each failure criterion from the triaxial compression tests. Each failure criterion is given as follows.

Mohr-Coulomb

$$
\frac{\sigma_{1}}{\sigma_{3}}=\frac{1-\sin \phi}{1+\sin \phi}
$$

Lade \& Duncan

$$
\frac{I_{1}^{3}}{I_{3}}=k_{1}
$$

SMP

$$
\frac{I_{1} I_{2}}{I_{3}}=k_{2}
$$

where $I_{1}, I_{2}$ and $I_{3}$ are stress invariants calculated from $\sigma_{1}, \sigma_{2}$ and $\sigma_{3}$; with $k_{1}$ and $k_{2}$ as constant values. $I_{1}, I_{2}$ and $I_{3}$ are calculated using the following equations.

$$
\begin{gathered}
I_{1}=\sigma_{1}+\sigma_{2}+\sigma_{3} \\
I_{2}=\sigma_{1} \sigma_{2}+\sigma_{2} \sigma_{3}+\sigma_{1} \sigma_{3} \\
I_{3}=\sigma_{1} \sigma_{2} \sigma_{3}
\end{gathered}
$$

Hence, the relationship between $\eta$ and $\theta$ can be expressed as follows:

Mohr-Coulomb

$$
\eta=\frac{6 \sin \phi}{\sqrt{3}(1+\sin \phi) \sin \theta+(3-\sin \phi) \cos \theta}
$$

Lade \& Duncan

$$
\begin{gathered}
\eta=\frac{1}{2 \sqrt{C / 3} \cos \alpha} \\
\alpha=\frac{1}{3} \cos ^{-1} \frac{D}{2 \sqrt{C / 3}^{3}} \cos 3 \theta \\
C=\frac{k_{1}}{3\left(k_{1}-27\right)} \\
D=-\frac{2 k_{1}}{27\left(k_{1}-27\right)}
\end{gathered}
$$

SMP

$$
\begin{gathered}
\eta=\frac{1}{2 \sqrt{C / 3} \cos \alpha} \\
\alpha=\frac{1}{3} \cos ^{-1} \frac{D}{2 \sqrt{C / 3}^{3}} \cos 3 \theta \\
C=\frac{1}{3} \frac{3+k_{2}}{9+k_{2}} \\
D=-\frac{2 k_{2}}{27\left(9+k_{2}\right)}
\end{gathered}
$$

Furthermore, the relationship between load angle $\theta$ and the intermediate stress coefficient $b$ is given as follows: 


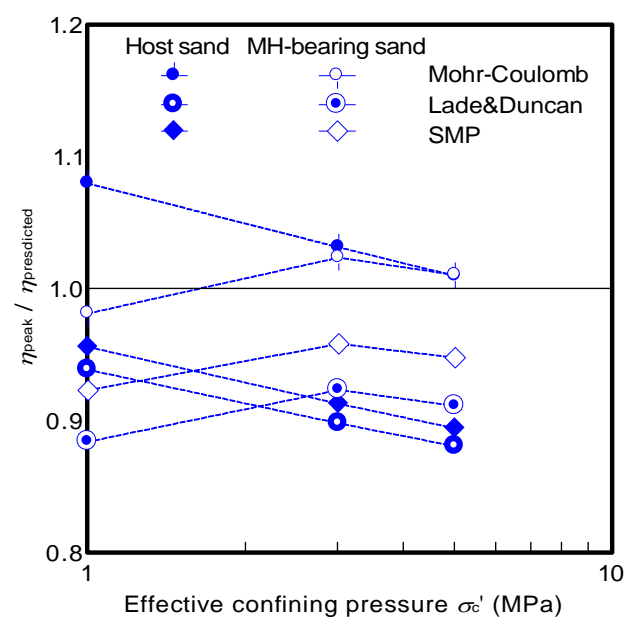

Fig. 8. Effect of confining pressure on $\eta_{\text {peak }} / \eta_{\text {predicted }}$
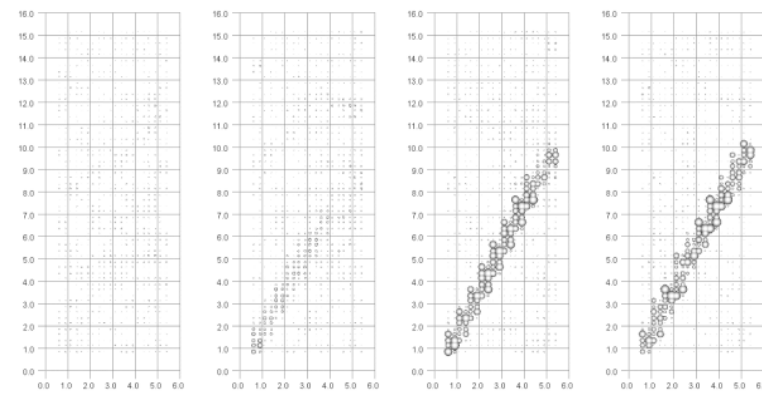

$1 \mathrm{a}-2 \mathrm{a}$

\begin{abstract}
$3 a-4 a$
\end{abstract}
(A) Incremental maximum shear strain.

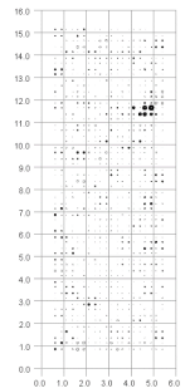

$1 \mathrm{a}-2 \mathrm{a}$

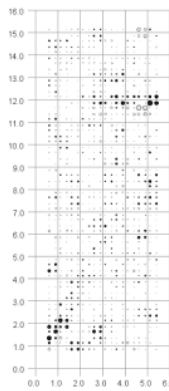

$2 a-3 a$

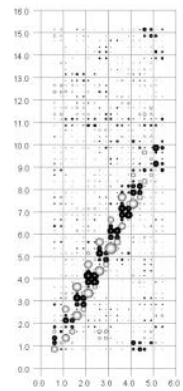

$3 a-4 a$

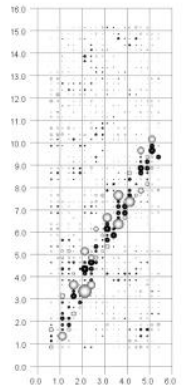

$4 a-5 a$

(B) Incremental volumetric strain.

Fig. 10. Illustration of localized incremental strain for $\mathrm{MH}-$ bearing sand. Each number represents closed circles in Fig. 2c.

$$
b=\frac{2 \tan \theta}{\sqrt{3}+\tan \theta}
$$

The intermediate principal stress value $b$ needs to be determined in order to calculate the stress invariants as $\sigma_{2}$ was not measured during shear. The $b$ value can be calculated as follows:

$$
b=\frac{\sigma_{2}-\sigma_{3}}{\sigma_{1}-\sigma_{3}}
$$

Tatsuoka et al. [1988] and Tsutsumi et al. [2008] have indicated that the $b$ value at peak stress ratio is $0.20 \sim 0.30$ for any confining pressure. Therefore, the $b$ value used in calculating $\sigma_{2}$ is 0.25 for these test results.

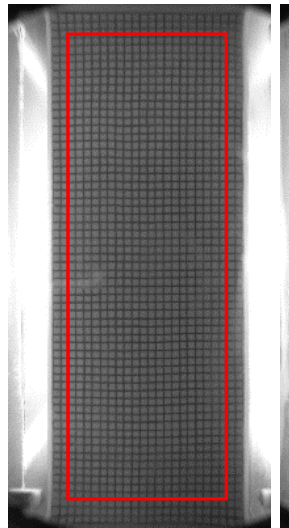

(a)

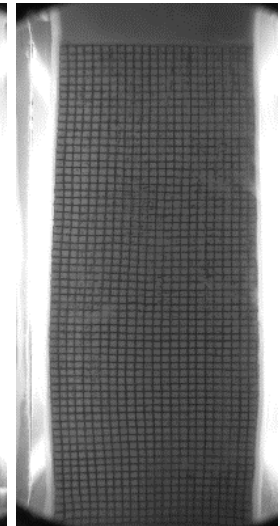

(b)

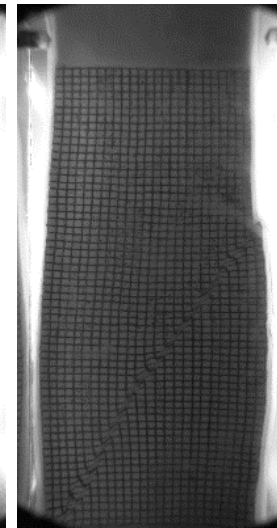

(c)
Fig. 9. Images for (a) initial level, (b) peak strength level, (c) residual strength level.

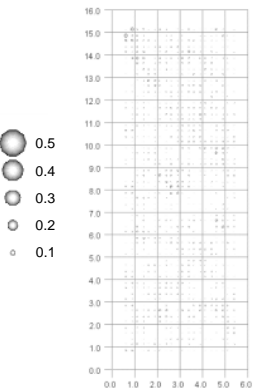

$1 b-2 b$

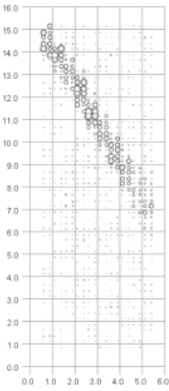

$2 b-3 b$

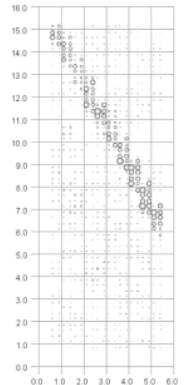

$3 b-4 b$

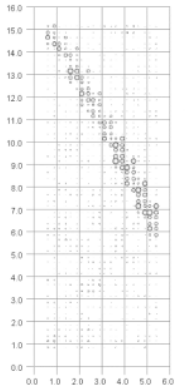

$4 b-5 b$
(A) Incremental maximum shear strain.

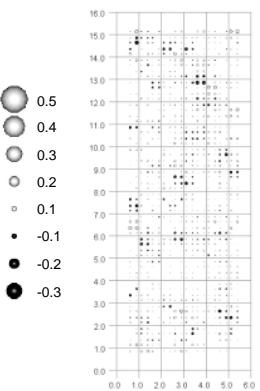

$1 b-2 b$

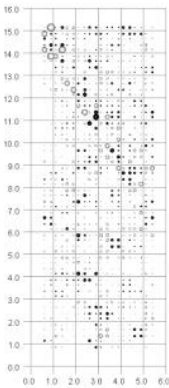

$2 b-3 b$

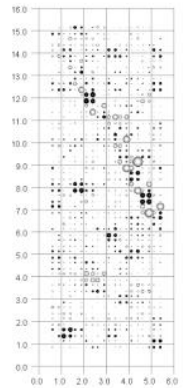

$3 b-4 b$
(B) Incremental volumetric strain

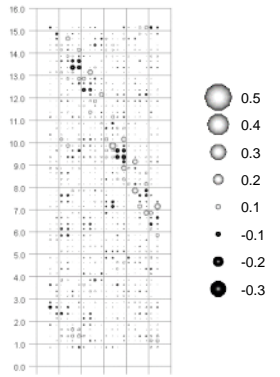

$4 b-5 b$

Fig. 11. Illustration of localized incremental strain for host sand. Each number represents open circles in Fig. 2c.

Figure 7a shows the relationship between the intermediate principal stress value $b$ and the peak stress ratio at every confining pressure. From Fig. 7a, in the case of host sand, the peak stress ratio is close to the SMP failure criterion. As confining pressure increases (Fig. 7b and $7 \mathrm{c}$ ), however, the peak stress ratio comes closer to the Mohr-Coulomb failure criterion. In the case of $\mathrm{MH}-$ bearing sand, the peak stress ratio is located between the SMP failure criterion and the Mohr-Coulomb failure criterion. Figure 8 shows the relationship between the confining pressure and the proportion of the peak stress ratio from test results with the peak stress ratio calculated from the failure criterions. The failure criterion is 
appropriate to predict the peak stress of a granular material if the value of $\eta_{\text {peak }} / \eta_{\text {predicted }}$ is close to 1 . From Fig. 9, it would seem that the Mohr-Coulomb failure criterion is useful at higher confining pressures, however SMP failure criterion is reasonable enough to use under low confining pressures.

\section{LOCALIZATION OF DEFORMATION}

Figure 9 shows examples of the progress of deformation when the effective confining pressure $\sigma_{3}{ }^{\prime}$ is $5 \mathrm{MPa}$. Localization of deformation can be observed by the naked eye as a shear band at residual strength (Fig. $9 b$ ), though the localization of deformation cannot be observed at peak strength (Fig. 9c). Image analysis was performed using images at different stages of loading within a square frame (Fig. 9a). An illustration of maximum shear strain increment is shown in Fig. 10A. From these figures it can be observed that localization of deformation did not appear before the peak stress ratio, but rather developed gradually from the bottom-left of the specimen after the peak stress ratio. The shear band appeared completely at the residual stress ratio. An illustration of the volumetric strain increment is shown in Fig. 10B. During softening (3b-4b), volumetric expansion and compression occurred in the shear band due to dilatancy. After reaching the residual strength (4b$5 b)$, volumetric expansion disappeared gradually while volumetric compression increased. Similarly, Fig. 11 shows the results of host sand. Figure 11A indicates that the shear band occurred from the upper-left area of the specimen. From Fig 11B, illustration of volumetric strain increment did not occur clearly in the shear band due to particle crushing.

\section{CONCLUSIONS}

In this study, the effects on MH-bearing sand and its host sand under plane strain conditions at various confining pressures have been shown. Furthermore, the local deformation of $\mathrm{MH}$-bearing sand and its host sand was shown using analysed photographs of specimens taken during shear tests. In a conventional manner, the stress ratio of $\mathrm{MH}$-bearing sand and its host sand increased more markedly in the plane strain tests compared with the triaxial tests at each confining pressure. Moreover, the peak stress ratio of $\mathrm{MH}$-bearing sand was higher than that of host sand as shown in previous research. In order to predict the failure strength, failure criterion appropriate for granular material was applied for MH-bearing sand and its host sand. The failure strength at every confining pressure was between the SMP criterion and Mohr-Coulomb criterion in the case of MH-bearing sand. However, the failure strength for host sand shifted from the SMP criterion to the MohrCoulomb criterion as the confining pressure increased, due to particle crushing. Localization of deformation occurred intensively in the shear band for MH-bearing sand and its host sand. However, expansive volumetric dilation occurred dominantly due to $\mathrm{MH}$ forming aggregate structures.

\section{REFERENCES}

1) Arthur, J. R. F., Dunstan, T., Al-Ani, Q. A. J. L., Assade, A., 1977. Plastic deformation and failure in granular media. Geoteqchniue 27 (1), pp. 53-74.

2) Desrues, J., Lanier, J., Stutz, P., 1985. Localization of the deformation in tests on sand sample. Engineering Facture Mechanics 21 (4) pp. 909-921.

3) Hyodo, M., Yoneda, J., Yoshimot, N., Nakata, Y., 2013. Mechanical and dissociation properties of methane hydratebearing sand in deep seabed, Soil and Foundations, 53(2), 299314.

4) Kvenvolden, K.A., Ginsburg, G.D., Soloviev, V.A., 1993. Worldwide distribution of subaquatic gas hydrates. GeoMarine Letters 13, pp. 32-40.

5) Masui, A., Miyazaki, K., Haneda, H., Ogata, Y., Aoki, K., 2008. Mechanical characteristics of natural and artificial gas hydrate bearing sediments. Proceedings of the 6th International Conference on Gas Hydrates.

6) Miyazaki, K., Yamaguchi, T., Sakamoto, Y., Tenma, N., Ogata, Y., Aoki, K., 2010. Effect of confining pressure on mechanical properties of sediment containing synthetic methane hydrate. Journal of MMIJ 126 (7), 408-417 (in Japanese).

7) Waite, W.F., Santamarina, J.C., Cortes, D.D., Dugan, B., Espinoza, D.N., Germaine, J., Jang, J., Jung, J.W., Kneafsey, T.J., Shin, H., Soga, K., Winters, W.J., Yun, T.-S., 2009. Physical properties of hydrate-bearing sediments. Reviews of Geophysics 47, RG4003.

8) Miyazaki, K., Masui, A., Sakamoto, Y., Aoki, K., Tenma, N., Yamaguchi, T., 2011. Triaxial compressive properties of artificial methane-hydrate-bearing sediment. Journal of Geophysical Research 116, B06102.

9) Nakata, Y., Hyodo, M., Yoshimoto, N., Quio, H., Kajiwara, T., 2010. Shear behavior of sand in plane strain compression test with PIV analysis. Japan Society of Civil Engineers 2010 Annual Meeting 65 III-254, pp. 507-508 (in Japanese).

10) Roscoe, K. H., 1970. The influence of strain in soil mechanics. Geoteqchniue 20 (2), pp. 129-170.

11) Tatsuoka, F., Nakamura, S., Huang, C. C., Tani, K., 1900. Strength anisotropy and shear band direction in plane strain tests of sand. Soils and Foundation 30 (1), pp. 35-54.

12) Tatsuoka, F., Nakamura, S., Huang, C. C., Tani, K., 1900. Strength anisotropy and shear band direction in plane strain tests of sand. Soils and Foundation 30 (1), pp. 35-54.

13) Tsutsumi, Y., Koseki, J. and Sato, T., 2008. Strain localization characteristics of dense Toyoura sand in plane strain compression tests under defferent confining pressures, Deformational Characteristics of Geomaterials 1, pp. 365-370.

14) Yun, T. S., Santamarina, J. C., Ruppel, C., 2007. Mechanical properties of sand, silt, and clay containing tetrahydrofuran hydrate. Journal of geophysical research 112, B04106. 